\title{
LVIII. Complete theory of the bifilar magnetometer and new methods for the determination of the absolute horizontal intensity of the Earth's magnetism, as well as of the temperature and induction-coefficients of magnets
}

\section{H. Wild}

To cite this article: $\mathrm{H}$. Wild (1880) LVIII. Complete theory of the bifilar magnetometer and new methods for the determination of the absolute horizontal intensity of the Earth's magnetism, as well as of the temperature and induction-coefficients of magnets, Philosophical Magazine Series 5, 9:58, 443-445, DOI: 10.1080/14786448008626868

To link to this article: http://dx.doi.org/10.1080/14786448008626868

\section{Published online: 28 Apr 2009.}

\section{Submit your article to this journal 둔}

Џll Article views: 4 
cessful as the inventor, Prof. Bell, and others anticipated. But instead of this, the instrument will undoubtedly become of the greatest assistance to physical research. In addition to signalling across rivers already referred to, Mr. Schwendler had already used the telephone for indicating the speed of the induction cylinder of a dynamoelectric machine (see précis of his Electric Light Report); and Professor Hughes has used it with great success in his induction-balance. It seems, in fact, the telephone is too sensitive and too quick working for practical use.

Calcuttr, April 27th, 1880.

LVIII. Complete Theory of the Bifilar Magnetometer and new Methods for the Determination of the Absolute Horizontal Intensity of the Earth's Magnetism, as well as of the Temperature and Induction-coefficients of Magnets. By H. WILD*.

THE above is the title of a communication made to the 1 Imperial Academy of Sciences of St. Petersburg on the 15th (27th) January, 1880 (Bull. Acad. Impér. Sci. St. Pétersburg, Mélanges Phys. et Chim. xi.), as an abstract of a more detailed paper to be shortly laid before the Academy.

The starting-point of the paper is the observation that the indications of the bifilar magnetometer, even when all causes of disturbance are excluded, differ from the results of direct measures of horizontal intensity to a far greater extent than can be accounted for by errors of observation. The author traces the cause of these discrepancies in the twisting of the suspending fibres, of which no account is taken in the ordinary theory of the bifilar magnetometer, according to which the moment of the directive couple of the suspension is ascribed simply to the weight of the magnet and its stirrup. The effect which this cause is capable of producing may either be calculated from the dimensions and coefficient of torsion-elasticity of the fibres, or it may be determined experimentally upon the bifilar instrument itself by observing the period of vibration before and after a known change has been made in the moment of inertia. Concordant determinations by both methods indicated that in the case of a bifilar suspended by brass wires 4 metres long, the couple due to torsion amounted to 1 per cent. of that due to the suspended weight. In the bifilar magnetometer of the St.-Petersburg magnetograph, which was suspended by steel wires only 0.3 metre long, the effect of torsion was as much as about 7 per cent. of the gra-

* Communicated by the Physical Society 
vitation-couple. On the other hand, it amounted to only 0.3 per cent. in a bifilar of the Pawlowsk Observatory, this instrument having cocoon fibres $1 \cdot 2$ metre long. From the consideration of the conditions which determine the magnitude of the torsion and gravitation-couples respectively, Prof. Wild concludes that it is not probable that the proportion between them can be reduced much below that which exists in the last-mentioned instrument, namely 0.3 per cent., and hence that the correction for torsion cannot be of negligible amount in accurate observations.

When this correction is applied, as well as that for induction, the author finds that the differences between the results of calculation and experiment disappear, and that very nearly identical values of the characteristic magnitude of the bifilar magnetometer, namely the so-called "torsion-angle" $z$, are obtained by both methods. The reader may be remincied that this angle $z$ is the angle which a vertical plane passing through the upper ends of the suspending fibres makes with a vertical plane through their lower ends when the magnet is perpendicular to the magnetic meridian. If $\mathrm{D}$ be the moment of the directive couple due to the suspension, $H$ the earth's horizontal intensity, and $\mathrm{M}$ the moment of the magnet, the angle $z$ is defined by the equation

$$
\mathrm{D} \sin z=\mathrm{HM} \text {. }
$$

Its magnitude may be found by direct experiment; or it may be calculated from the periods of vibration of the magnet observed when its position of equilibrium is in the magnetic meridian and its north-seeking pole is towards magnetic north and its south-seeking towards magnetic south respectively. If $t_{1}$ and $t_{2}$ are the periods in the two cases,

$$
\sin z=\frac{t_{2}^{2}-t_{1}^{2}}{t_{2}^{2}+t_{1}^{2}}
$$

The author observes, in the next place, that the direct determination of $z$, together with the observation of the periods $t_{1}, t_{2}, t_{3}$ (the last being the period of vibration when the position of equilibrium of the magnet is perpendicular to the meridian), affords an excellent method for determining separately the two induction-coefficients of the magnet, namely the coefficient of increase and that of decrease of the magnetic moment. The advantages of this method are chiefly that it does not depend upon the mutual action of two magnets, which can be only approximately calculated, and that it requires the use of only one instrument. He also remarks that these advantages apply also to the method indicated by him in a previous 
publication for the determination of the temperature-coefficients of magnets, and that he has assured himself by actual trial of the precision of this method.

The remainder of the paper is devoted to the description of a process for determining in absolute measure the earth's horizontal magnetic intensity by means of the bifilar magnetometer, and to the statement of the formula required for the complete reduction of the results so as to take account of all corrections. The principles involved in this process may be thus indicated:-It is divisible, like Gauss's process, into a method for determining $(a)$ the product of the horizontal intensity $\mathrm{H}$ into the moment $\mathrm{M}$ of a particular magnet, and $(b)$ the ratio of the same two quantities. To determine the product, the magnet is suspended in the bifilar instrument, and the torsionangle $z$ is observed which is required to set the axis of the magnet perpendicular to the meridian. This operation gives the equation

$$
\mathrm{D} \sin z=\mathrm{HM} \text {. }
$$

The ratio of $\mathrm{H}$ to $\mathrm{M}$ is found by suspending another magnet of moment $\mathbf{M}^{\prime}$ in the bifilar, placing the first magnet with its axis in the magnetic meridian through the centre of suspension of the instrument, and determining the torsion-angle $z_{1}$, needed to set the suspended magnet perpendicular to the meridian when the north-seeking pole of the first magnet (moment M) is towards magnetic north, and also the corresponding angle $z_{2}$, when the north-seeking pole of the first magnet is towards magnetic south. These observations give, subject to the proper corrections, the equations

$$
\begin{aligned}
& \mathrm{D}^{\prime} \sin z_{1}=\left(\mathrm{H}+\frac{2 \mathrm{M}}{r^{3}}\right) \mathrm{M}^{\prime}, \\
& \mathrm{D}^{\prime} \sin z_{2}=\left(\mathrm{H}-\frac{2 \mathrm{M}}{r^{3}}\right) \mathrm{M}^{\prime} ;
\end{aligned}
$$

from which the ratio in question is easily obtained in terms of $z_{1}, z_{2}$, and the distance $r$ between the centres of the magnets. The horizontal intensity is then given by an expression which, when the corrections (for which we must refer to the original paper) are omitted, becomes

$$
\mathrm{H}^{2}=\frac{2 \mathrm{D} \sin z}{r^{3}} \cdot \frac{\sin z_{1}+\sin z_{2}}{\sin z_{1}-\sin z_{2}}
$$

